\title{
B Cell Monoclonality of Intraoculalr Lymphoma and Breast Lymphoma
}

Kouichi Ohta, $\mathrm{MD}^{1}$, Kenji Sano, $\mathrm{MD}^{2}$, Takao Hirano, $\mathrm{MD}^{1}$, Tomoko Sugimoto, $\mathrm{MD}^{1}$ and Takanobu Kikuchi, $\mathrm{PhD}^{3}$

${ }^{1}$ Department of Ophthalmology, ${ }^{2}$ Department of Laboratory Medicine, and ${ }^{3}$ Department of Instrumental Analysis Research Center for Human and Environmental Science, Shinshu University School of Medicine, Matsumoto, Japan.

Short title: Identical B cell monoclonality in metastatic intraocular lymphoma Corresponding author: Kouichi Ohta, MD, Department of Ophthalmology, Shinshu University School of Medicine, 3-1-1 Asahi, Matsumoto 390-8621 Nagano, JAPAN. Phone: +81-263-37-2664

Fax: $\quad+81-263-32-9448$

e-mail: kohta@hsp.md.shinshu-u.ac.jp

Property interest category: $\mathrm{N}$.

Key words; B cell monoclonality, intraocular lymphoma, metastasis, vitrectomy Word count: 497

Figures: 2 
Ohta et al.

\section{Summary}

B cell monoclonal gene rearrangements have been reported in several cases of primary intraocular lymphoma and primary central nervous system lymphomas. Such molecular analysis has been performed on only one case of a primary testicular and a metastatic intraocular lymphoma. However, the gene rearrangements differed at the two sites. We present a case in which B cell monoclonality was found in an intraocular lymphoma and a primary breast lymphoma. 
Intraocular non-Hodgkin's lymphomas are uncommon malignant tumors derived from two types of lymphomas; a primary central nervous system lymphoma (PCNSL) and a systemic lymphoma. Compared with primary intraocular lymphomas (PIOLs), the prevalence of metastatic systemic lymphomas is much lower ${ }^{1,2)}$. The diagnosis of intraocular lymphomas remains problematic because of the high number of false-negative diagnoses made from analysis of vitrectomy specimens. Molecular analysis of the immunoglobulin heavy chain (IgH) gene rearrangements ${ }^{3,4)}$ and ocular cytokine levels, e.g., elevated interleukin (IL)-10 with an IL-10/IL-6 ratio >1.0, are helpful adjuncts for a diagnosis ${ }^{2,5)}$. Coupland et al reported B cell monoclonal gene rearrangements in several cases of PIOL and PCNSL ${ }^{6,7)}$. Bilateral imonoclonality in PIOLs has also been reported ${ }^{8)}$. The molecular analysis approach was performed on only one non-PCNSL case ${ }^{9}$, and the IgH gene rearrangements were different for the testicular and intraocular lymphomas.

We report a case of non-PCNSL with identical monoclonal gene rearrangements in the vitreous and breast tumors.

\section{Case report}

A 61-year-old woman was diagnosed non-Hodgkin's lymphoma of the breast in January 2005 (figs. 1A, 1B). The right orbital tumor developed without an intraocular involvement. She received cyclophosphamide, doxorubicin, vincristine, and prednisone (CHOP) therapy with rituximab for eight sessions and was in remission for 6 months. Because of a 3-month history of floaters and decreased vision of her left eye, she was referred to us in June 2006. Her visual acuity (VA) was 20/20 OD and 10/20 OS. The vitreous opacity was moderate and small white dots were scattered in the posterior pole of her left eye (fig. 2A). Fluorescein angiography revealed hyperfluorescence at the white spots and dye leakage from the retinal vessels. Diagnostic 23-gauge vitrectomy combined with cataract surgery was performed. Unfortunately, the collected cells were sensitive and were not preserved. The IL-10 level in the vitreous was 3,460 pg/ml and IL-6 was $165 \mathrm{pg} / \mathrm{ml}$.

DNA was extracted from the vitrectomy sample and from paraffin-embedded breast tissues obtained earlier, and semi-nested PCR with primers for the CDR III locus of IgH was performed ${ }^{10}$. The same sized bands were detected in both samples (fig. $1 \mathrm{C}$ ), and direct sequencing of the PCR products revealed identical monoclonal rearrangements of the IgH gene.

She was diagnosed with an intraocular tumor that metastasized from the breast tumor. After radiation therapy (30 Gy) for both eyes, vitreous opacity and the number of white spots decreased (fig. 2B).

\section{Comments}

Our results showed that the ocular and breast tumors were B cell lymphomas, and their DNA 
Ohta et al.

had identical monoclonal rearrangements of the IgH gene. To the best of our knowledge, our case represents the first that has been reported where molecular analysis proved that the lymphomatous manifestations of a intraocular lymphoma consisted of identical neoplastic B cells that were derive from the same precursor cells.

The identical IgH gene rearrangement suggests that the intraocular lymphoma resulted from a metastasis of the same neoplastic clone rather than a simultaneous neoplastic formation of multiple B cell clones. 
Ohta et al.

\section{References}

1 Witcup SM, de Smet MD, Rubin BI, et al. Intraocular lymphoma. Clinical and histopathological diagnosis. Ophthalmology 1993;100:1399-1406.

2 Chan CC, Buggage RR, Nussenblatt RB. Intraocular lymphoma. Curr Opin Ophthalmol 2002;6:411-418.

3 Katai N, Kuroiwa S, Fujimori K, Yoshimura N. Diagnosis of intraocular lymphoma by polymerase chain reaction. Graefes Arch Clin Ophthalmol 1997;235:431-436.

4 Shen DF, Zhuang Z, LeHoang P, et al. Utility of microdissection and polymerase chain reaction for the detection of immunoglobulin gene rearrangement and translocation in primary intraocular lymphoma. Ophthalmology 1998;105:1664-4669.

5 Chan CC, Witcup SM, Solomon D, Nussenblatt RB. Interleukin-10 in the vitrous of patients with primary intraocular lymphoma. Am J Ophthalmol 1995;120:671-673.

6 Coupland SE, Hummel M, Stein H, et al. Demonstration of identical clonal derivation in a case of “oculocerebral” lymphoma. Br J Ophthalmol 2005;89:238-251.

7 Coupland SE, Hummel M, Müller $\mathrm{H}-\mathrm{H}$, et al. Molecular analysis of immunoglobulin genes in primary intraocular lymphoma. Invest Ophthalmol Vis Sci 2005;46:3507-3514

8 Higashide T, Takahira M, Okumura H, Torisaki M, Sakurai M, Shirao Y, Sugiyama K. Bilaterally identical monoclonality in a case of a primary intraocular lymphoma. Am J Ophthalmol 2004;138:306-308.

9 Wallace DJ, Altemare CR, Shen DF, et al. Primary testicular and intraocular lymphomas: Two case reports and review of the literature. Surv Ophthalmol 2006;51:41-50.

10 Tojo K, Hattori T, Ito T, Asano N, Sano K, Suzuki T, Maruyama K. Multiple brain tumors of diffuse large B cell lymphoma in a patient with Waldstrom's macroglobulinemia/lymphoplasmatic lymphoma: PCR and DNA sequence analysis show evidence of differences in clonality of the two B cell malignancies. Internal Medicine 2004;43:990-996. 
Ohta et al.

\section{Figure legends}

Figure 1. Histopathological and polymerase chain reaction examination of breast and intraocular lymphomas.

(A) Histopathological examination of neoplastic lymphocytes in the breast lymphoma (hematoxylin-eosin, original magnification x 400). The specimen shows an infiltration of diffuse large cells with oval nucleoli.

B. Immunohistochemical stain with CD20 (original magnification x 400). Results show that the surface of almost all abnormal cells express CD20.

C. Polymerase chain reaction (PCR) analysis of paraffin-embedded sections (breast) and pellets from the vitreous. Semi-nested PCR for the immunoglobulin heavy chain run on 3\% agarose gel stained with ethidium bromide (Lane M: DNA molecular weight marker (pBR322/HinfI digest); Lane 1: positive control (Raji cell line); Lane 2-4: breast; Lane 5: vitreous specimen; Lane 6: normal control (healthy donor); Lane 7: no template control) There are identical patterns of IgH gene rearrangement at the CDR3 sites between the breast and intraocular lymphomas.

Figure 2. Fundus photograph before and after treatment.

A. Photograph of the left eye showing hazy fundus due to the diffuse vitreous opacity. Many small yellowish-white infiltrates can be seen at the posterior pole and temporal retina. B. Photograph of same eye 4 months after surgery and 3 months after irradiation. The chorioretinal lesions are not present or have been transformed to the scar lesions. 

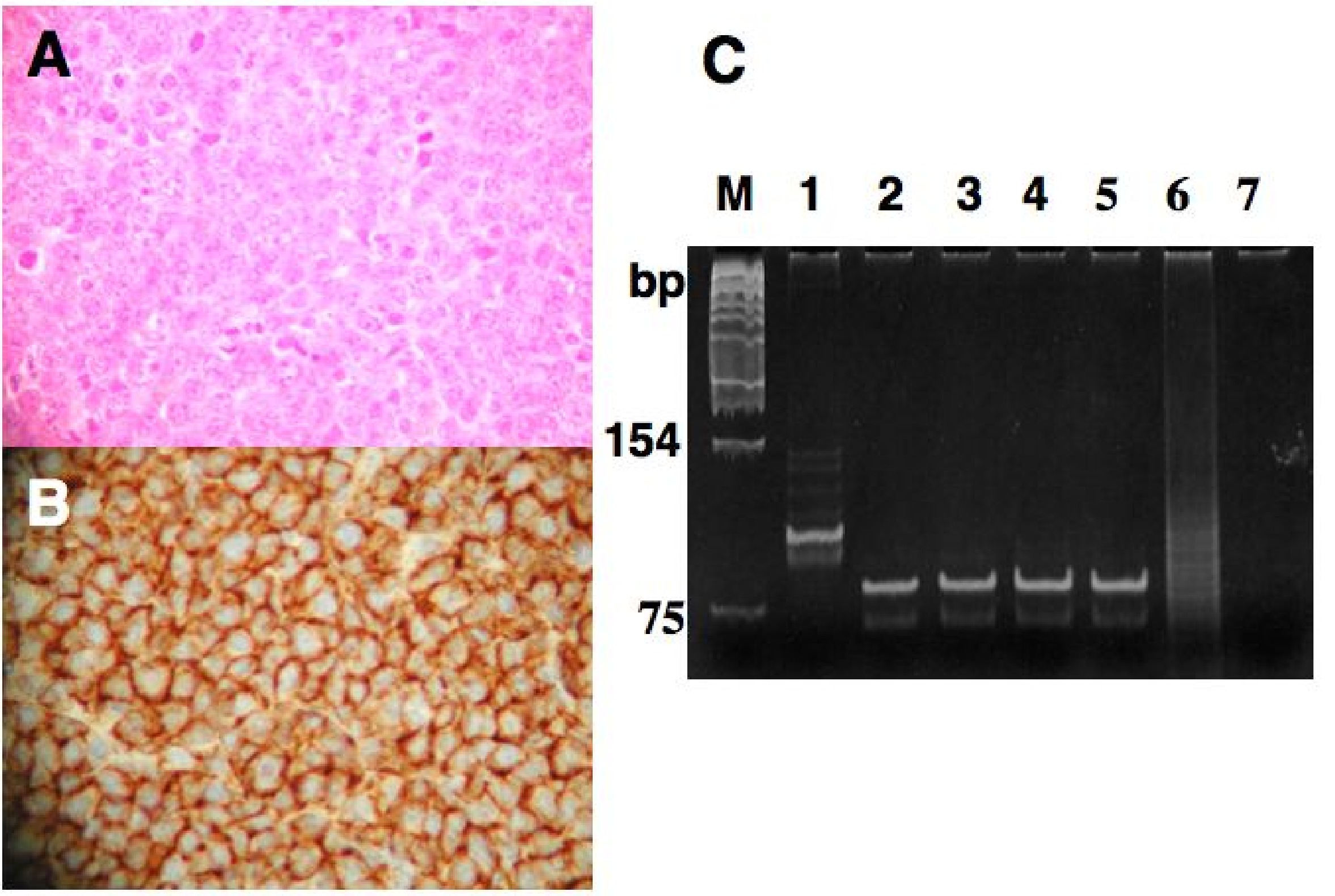
